\title{
Blister beetle dermatitis: A seasonal occurrence
}

\author{
Manouri P Senanayake ${ }^{1}$, Arundathi Jayasena ${ }^{2}$, Vanathy Varathan ${ }^{3}$, S Kamaladeepan ${ }^{2}$
}

Sri Lanka Journal of Child Health, 2011; 40: 34

(Key words: Blister beetle dermatitis; seasonal)

Blister Beetle Dermatitis is a cutaneous eruption caused by contact with body fluids of beetles ${ }^{1}$. We report this patient because the causative insect is often unnoticed and therefore a high degree of suspicion is necessary for diagnosis.

\section{Case report}

A 4 year old boy presented with crusted skin lesions of bizarre shapes on the face and trunk. He was generally well apart from fever. Multiple eczematous lesions of varying sizes, with necrotic centres were seen on the face, upper chest and upper limbs. 'Kissing lesions' were observed on the flexor surface of the left elbow. Parallel linear lesions seen on the chest were compatible with scratch marks (Figure 1). Some lesions had a purulent discharge due to secondary infection. Potassium permanganate solution compresses, 1\% hydrocortisone cream topically and antihistamines and cloxacillin orally resulted in rapid healing with minimal or no scarring.

\section{Discussion}

Contact with body fluids of the incriminated beetle occurs when the insect settles on and is accidentally crushed against the skin. The resulting skin lesions characteristically occur on exposed areas; usually face, neck and upper extremities ${ }^{3}$. Our patient showed lesions at sites where he had touched or scratched himself with contaminated fingers.

Outbreaks of blister beetle dermatitis have been aetiologically linked with several species of beetles (order: Coleoptera, family: Staphylinidae, genus: Paederus) and are reported to occur between May and July in Sri Lanka ${ }^{1,2}$.

${ }^{1}$ Professor in Paediatrics, University of Colombo, ${ }^{2}$ Registrar in Paediatrics, ${ }^{3}$ Senior Registrar in Dermatology, Lady Ridgeway Hospital for Children, Colombo

(Received on 26 October 2010. Accepted on 26 November 2010)
Our observation of five children from different locations in and around Colombo, in May 2010 is in keeping with this seasonal occurrence.

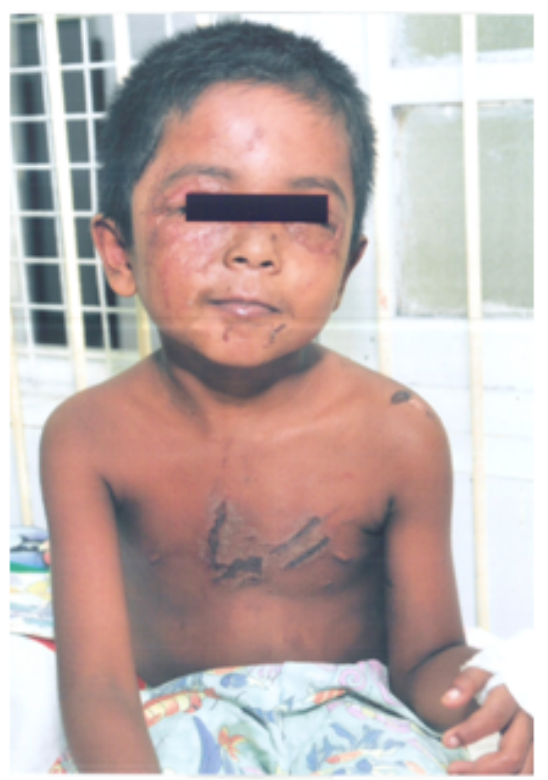

Figure 1: Staphylinid blister beetle dematitis in a Sri Lankan child

\section{References}

1. Grekin RC, Samalaska CP, Vin-Christian K. Parasitic infestation, stings and bites. In: Odom RB, James WD, Berger TG, eds. Andrew's diseases of skin (9th ed.), Philadelphia : WB Saunders, 2000; 526-73.

2. Brazzetti V, Martinoli S, Prestinari F, Staphylinid blister beetle dermatitis. Contact dermatitis 2002; 46(3): 183-4.

3. Kamaladasa SD, Perera WD, Weeratunge L. An outbreak of Paederus Dermatitis in a suburban hospital in Sri Lanka. Int J Dermatol 1997; 36(1): 34-6. 